Meta-Analysis

\title{
Digital Subtraction Angiography Versus Real- Time Fluoroscopy for Detection of Intravascular Penetration Prior to Epidural Steroid Injections: Meta-Analysis of Prospective Studies
}

Ognjen Visnjevac, MD¹, Paul Kim, MD², Sina Farid-Davari, MD, Patrick Johnson, MD, and Nader Djalal Nader, MD, PhD ${ }^{1}$

From: ${ }^{1}$ Department of Anesthesiology, University at Buffalo, Buffalo, NY; 2 Department of Anesthesiology and Pain Medicine, Beth Israel

Deaconess Medical Center, Harvard Medical School, Boston, $\mathrm{MA}$

Drs. Visnjevac, Farid-Davari, and Johnson are Residents, with teh Department of Anesthesiology, University at Buffalo, Buffalo, NY. Dr. Kim is a Pain Fellow, Department of Anesthesiology and Pain Medicine, Beth Israel

Deaconess Medical Center, Harvard Medical School, Boston, MA. Dr. Nader is a

Professor with the Department of Anesthesiology \& Surgery, University at Buffalo, Buffalo, NY

Address Correspondence: Nader Djalal Nader, MD Professor University of Buffalo Dept of Anesthesiology VAMC, Rm 202C 3495 Bailey Ave. Buffalo, NY 14215 E-mail: nnader@buffalo.edu

Disclaimer: Prior publication is limited to a poster presentation on this topic at the 2014 ASIPP National Meeting.

Dr. Nader was an employee of the U.S. Federal Government when this work was conducted and prepared for publication. Hence, it is not protected by the

Copyright Act, and copyright ownership cannot be transferred.

Manuscript received: 11-14-2014 Revised manuscript received: 12-11-2014 Accepted for publication: 12-18-2014

Free full manuscript: www.painphysicianjournal.com
Background: Neurological injury is a rare but devastating complication of epidural steroid injections (ESIs) generally thought to arise from neurovascular compromise. The use of real-time fluoroscopy (RTF) with contrast media is the most common preventative measure taken to avoid intravascular penetration. In 2002, it was proposed that digital subtraction angiography (DSA) might be more useful than RTF. Since then, several prospective studies have advocated for its use.

Objectives: As DSA is not currently a "gold standard," a meta-analysis was performed to compare the efficacy of DSA versus RTF for detection of intravascular penetration during ESI.

Study Design: Meta-analysis of prospective observational studies.

Methods: A targeted Pubmed search was conducted, yielding 49 reports and 4 manuscripts, which were analyzed using Review Manager Software (Rev Man 5.2). Inclusion/exclusion criteria: peer-reviewed prospective reports comparing the sensitivity of DSA to RTF in the same individuals without change in needle position between comparative imaging. Pooled estimate of odds ratios with $95 \%$ confidence interval using a random effect model was applied.

Results: There were a total of 188 intravascular events from 1,290 ESIs performed. RTF was able to detect 148 events with DSA detecting an additional 40 events missed by RTF. No major neurological complications were reported. DSA had a statistically significant favorable odds ratio over RTF for detection of intravascular penetration during ESI (OR $=1.32$ [1.05-1.67]; $P=0.02$ ).

Limitations: Although the major methodological aspects of each study assessed in this metaanalysis were quite similar, there were small differences in needle gauge and the selection of secondary outcome measures. Despite attempts to minimize it, concern for operator bias also exists.

Conclusions: DSA had a $32 \%$ improvement $(O R=1.32)$ for detection of intravascular penetration with ESI when compared to RTF. Although this supports advocacy for use of DSA, it also suggests that there is a greater than $30 \%$ "missed-events" rate for detection of vascular penetration when using RTF for ESI, which does not correlate with the generally reported cumulative rates of complications (1\%). This discrepancy suggests that factors other than vascular events also play a role in complications. Nonetheless, given the evidence, we advocate for the increased use of DSA over RTF for transformational ESIs.

Key words: Digital subtraction angiography, real-time fluoroscopy, epidural steroid injection, complications, outcomes, pain imaging, chronic pain, intravascular injection, meta-analysis

Pain Physician 2015; 18:29-36 
$\mathrm{N}$ eurological injury is a rare but highly morbid complication of epidural steroid injections (ESI), often thought to arise from neurovascular compromise following intravascular penetration, steroid injection, or vascular spasm (1). A recent closed-claims report for pain-related lawsuits in the United States identified direct needle trauma as the most common cause of devastating cord injury $(31 \% ; 20$ of 64 claims), followed by cord infarction or stroke after intra-arterial injection (14\%; 9 of 64 claims) (2).

The most common preventative measure taken by interventional pain physicians is the use of real-time fluoroscopy (RTF) with injection of contrast media to avoid intravascular penetration. Vascular events occur more frequently with concurrent epidural spread, making their detection difficult, even with $\operatorname{RTF}(3,4)$. In 2002, it was proposed that digital subtraction angiography (DSA) might be useful for detecting intravascular injection by interventional pain physicians (5). Since then, several prospective studies have compared the sensitivity of DSA to RTF for detection of vascular events (6-10).

The primary objective of this study was to examine the beneficial role of DSA and in comparison to RTF in detection of inadvertent vascular penetration during ESI. DSA is not currently a "gold standard" point of care guiding tool for ESI. We have performed a meta-analysis of all studies that have examined such a comparison with the hypothesis that DSA would yield a significant improvement in detection of vascular events as compared to RTF.

\section{Methods}

\section{Database Search}

Using the search words "digital subtraction angiography epidural," "digital subtraction fluoroscopy epidural," and "digital subtraction fluoroscopy pain" the Google Scholar, PUBMED, EMBASE, and MEDLINE databases were searched. Relevant manuscripts' references were also searched for additional pertinent data. Search was not restricted by year or publication or language.

\section{Study Selection}

An initial eligibility screen of all retrieved titles and abstracts was conducted, and only prospective studies reporting data comparing DSA to RTF for detection of vascular events were selected for further review. The following specific criteria were used for final selection: (A) prospective studies only; (B) studies comparing DSA to RTF for detection of vascular events; (C) studies performing both types of comparative imaging (DSA and RTF) in each individual without repositioning of needle tip between imaging techniques. Retrospective studies were excluded, as were prospective studies comparing DSA to RTF individually in separate groups of patients. Indication for ESI was not factored into inclusion or exclusion criteria, but was noted in a summary of included studies (Table 1). Each study was evaluated by 2 authors (OV and NDN) for stated criteria and any disagreements were resolved with discussion.

\section{Data Extraction}

Characteristics of each study were extracted, which included the last name of the first author, publication year, study design, number of patients, mean age, indication for ESI, inclusion and exclusion criteria, and number of interventionalists involved. Finally, data regarding the incidence of vascular event detection rates were extracted per imaging technique for each study. The only secondary outcomes to be extracted consisted of clinically significant patient complications (Fig. 1).

\section{Quality Assessment}

Quality of each study was evaluated using the checklist developed by Downs and Black (11), which included 27 questions based on a study's reporting, external validity, bias, confounding, and power. Each question gave a score of 0 or 1 and the overall score ranges from 0 to 27 . Studies with scores of 23 or above were considered to be high quality, 18 to 22 were considered to be moderate quality, and scores below 18 were considered to be low quality.

\section{Statistical Methods}

RevMan 5.2 (Copenhagen, Denmark) was used to calculate the odds ratio (95\% confidence interval) for each study on the frequency of the positive DSA and RTF findings on intravascular penetrations. Pooled analysis was performed using the Der Simonian and Laird random effects model (12). The 4 studies that were analyzed were described in Table 1. Pooled estimate of odds ratios with $95 \%$ confidence interval using a random effect model was employed and represented in a forest plot.

\section{Results}

\section{Study Selection}

Forty-nine reports were screened, of which 44 


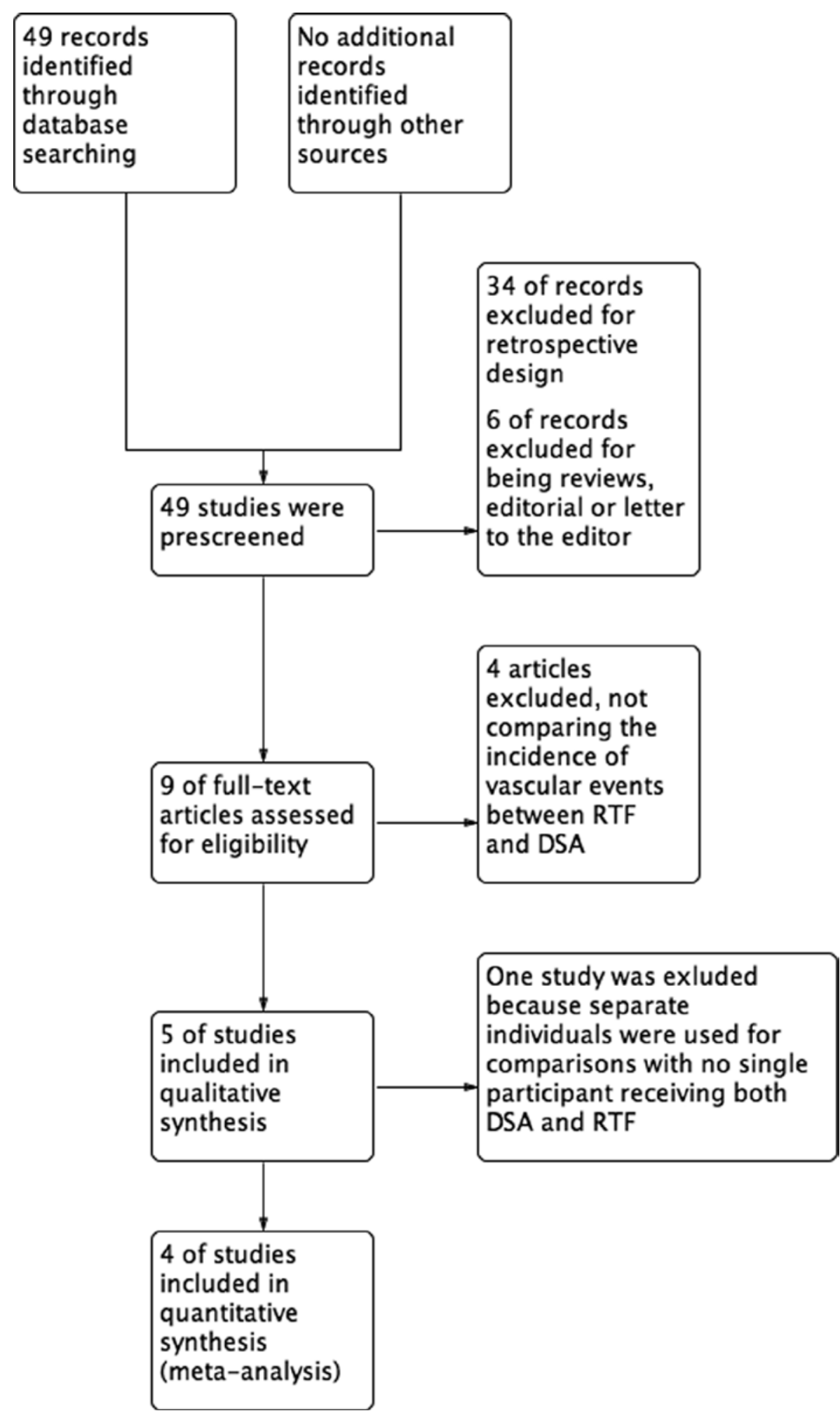

Fig. 1. Flow diagram of search and selection criteria for inclusion in this meta-analysis. 
Table 1. Characteristics of studies included for analysis.

\begin{tabular}{|l|c|c|c|c|c|c||}
\hline \multicolumn{1}{|c|}{ Study } & Study Design & N & Age* & Inclusion Criteria & Exclusion Criteria & $\begin{array}{c}\text { Number of } \\
\text { Interventionalists }\end{array}$ \\
\hline $\begin{array}{l}\text { Lee et al } \\
(2010)(9)\end{array}$ & $\begin{array}{c}\text { Prospective } \\
\text { Observational }\end{array}$ & 87 & 58.0 & HNP, FBSS, SS & $\begin{array}{c}\text { Interlaminar or caudal ESI, } \\
\text { pregnancy, allergy to components } \\
\text { used, difficulty during procedure }\end{array}$ & 5 physicians \\
\hline $\begin{array}{l}\text { Kim et al } \\
(2013)(8)\end{array}$ & $\begin{array}{c}\text { Prospective } \\
\text { Observational }\end{array}$ & 732 & 60.0 & $\begin{array}{c}\text { Back or radicular pain due } \\
\text { to HNP, FBS, SS, CF, or } \\
\text { herpes zoster }\end{array}$ & $\begin{array}{c}\text { Pregnancy, coagulopathy, } \\
\text { infection, allergy to components } \\
\text { used }\end{array}$ & 2 physicians \\
\hline $\begin{array}{l}\text { El Abd et al } \\
(2014)(7)\end{array}$ & $\begin{array}{c}\text { Prospective } \\
\text { Observational }\end{array}$ & 150 & 54.1 & $\begin{array}{c}\text { Discogenic axial back } \\
\text { or neck pain, radicular } \\
\text { leg or arm pain, lack of } \\
\text { response to conservative } \\
\text { management, age }>18 \text { years }\end{array}$ & $\begin{array}{c}\text { Pregnancy, tumor or metastases } \\
\text { involving the spine, infection, } \\
\text { spinal instability, coagulopathy, } \\
\text { allergy to components used, } \\
\text { steroid psychosis }\end{array}$ & 1 physician \\
\hline $\begin{array}{l}\text { Hong et al } \\
(2014)(6)\end{array}$ & $\begin{array}{l}\text { Prospective } \\
\text { Observational }\end{array}$ & $239^{* *}$ & 62.5 & HNP, FBSS, SS, CF & $\begin{array}{c}\text { Interlaminar or caudal ESI, } \\
\text { pregnancy, tumor or metastases } \\
\text { involving the spine, infection, } \\
\text { spinal instability, coagulopathy, } \\
\text { allergy to components used }\end{array}$ & 1 physician \\
\hline
\end{tabular}

HNP: herniated nucleus pulposus; FBSS: failed back surgery syndrome; SS: spinal stenosis; CF: compression fracture. ${ }^{*}$ Average age reported in years. ${ }^{* *} 10$ patients received 2 -level transforaminal ESI, assessed as 2 separate procedures and assessments

were excluded because they were one of the following: retrospective studies, case reports, reviews, editorials or letters, prospective studies not reporting the incidence of vascular events, or studies not comparing DSA to RTF. Of the 5 studies reviewed, one was excluded because the prospective comparison of DSA to RTF was done in different individuals, with each participant receiving either only DSA or only RTF, but not both (10).

\section{Study Characteristics}

Each of the studies utilized the transforaminal approach for ESI, with all 4 studies reporting data at lumbar levels, while 3 of 4 reported data at sacral levels, and only one reported data at the cervical level. Study designs included a moderate degree of homogeneity, as outlined in Table 1, and their variability is discussed with other limitations in the discussion section.

\section{Quality Assessments}

Each of the 4 studies analyzed scored between 19 and 21 points per the checklist developed by Downs and Black (11), resulting in a classification for being of moderate quality (Table 2). Each study sparingly lost points, but a cluster of 4 questions materialized where all 4 studies scored zero points. In these checklist questions, points were allocated for randomization of patients to control and intervention groups (one point), blinding of staff to group allocation until recruitment for the entire study was complete (one point), blinding of interventionalist(s) (one point) along with observers assessing output measures (one point). Since each study was designed for participants to receive both DSA and RTF and could not be randomized to receive just one or the other, the first 2 of the abovementioned points were automatically lost. The second set of 2 points was lost because interventionalists and observers were not blinded to the imaging technique being used.

\section{Meta-analysis of Detection of Vascular Events}

A total of 1,290 ESI were performed with an overall intravascular event detection of 148 by RTF and 188 by DSA. This reflected 40 false-negatives per RTF that were confirmed as positive vascular events with DSA. No false-negatives were reported for DSA and all positive events were considered to be true-positives. DSA was shown to have a statistically significant favorable odds ratio over classical RTF for detection of intravascular penetration during ESI (OR = 1.32, [1.05 - 1.67], $P=0.02$, Fig. 2). The sensitivity for RTF for detection of vascular events was $78.2 \%$ and specificity was $100 \%$. No major neurological complications were reported in the 4 studies included in this analysis.

\section{Discussion}

DSA was shown to have a greater than $30 \%$ increase in detection of intravascular penetration with ESI when compared to RTF (OR = 1.32, Fig. 2). Since vascular events have been reported to be more common 
Table 2. Quality assessments of studies included for analysis.

\begin{tabular}{|c|c|c|c|c|}
\hline & Kim & Hong & El Abd & Lee \\
\hline \multicolumn{5}{|l|}{ Reporting } \\
\hline Is the hypothesis/aim/objective of the study clearly described? & 1 & 1 & 1 & 1 \\
\hline Are the main outcomes to be measured clearly described in the Introduction or Methods section? & 1 & 1 & 1 & 1 \\
\hline Are the characteristics of the patients included in the study clearly described? & 1 & 1 & 1 & 1 \\
\hline Are the interventions of interest clearly described? & 1 & 1 & 1 & 1 \\
\hline Are the distributions of principal confounders in each group of subjects to be compared clearly described? & 1 & 0 & 0 & 1 \\
\hline Are the main findings of the study clearly described? & 1 & 1 & 1 & 1 \\
\hline Does the study provide estimates of the random variability in the data for the main outcomes? & 1 & 1 & 1 & 1 \\
\hline Have all important adverse events that may be a consequence of the intervention been reported? & 1 & 1 & 1 & 0 \\
\hline Have the characteristics of patients lost to follow-up been described? & 1 & 1 & 1 & 1 \\
\hline $\begin{array}{l}\text { Have actual probability values been reported ( e.g., } 0.035 \text { rather than }<0.05 \text { ) for the main } \\
\text { outcomes except where the probability value is less than } 0.001 \text { ? }\end{array}$ & 1 & 1 & 1 & 1 \\
\hline TOTAL: & 10 & 9 & 9 & 9 \\
\hline \multicolumn{5}{|l|}{ External Validity } \\
\hline $\begin{array}{l}\text { Were the patients asked to participate in the study representative of the entire population from which } \\
\text { they were recruited? }\end{array}$ & 0 & 1 & 1 & 1 \\
\hline $\begin{array}{l}\text { Were those patients who were prepared to participate representative of the entire population from which } \\
\text { they were recruited? }\end{array}$ & 0 & 1 & 1 & 0 \\
\hline $\begin{array}{l}\text { Were the staff, places, and facilities where the patients were treated representative of the treatment the } \\
\text { majority of patients receive? }\end{array}$ & 1 & 1 & 1 & 1 \\
\hline TOTAL: & 1 & 3 & 3 & 2 \\
\hline \multicolumn{5}{|l|}{ Internal Validity } \\
\hline Was an attempt made to blind study patients to the intervention they have received? & 0 & 0 & 0 & 0 \\
\hline Was an attempt made to blind those measuring the main outcomes of the intervention? & 0 & 0 & 0 & 0 \\
\hline If any of the results of the study were based on "data dredging," was this made clear? & 1 & 1 & 1 & 1 \\
\hline \multicolumn{5}{|l|}{$\begin{array}{l}\text { In trials and cohort studies, do the analyses adjust for different lengths of follow-up of patients, or in } \\
\text { case-control studies, is the time period between the intervention and outcome the same for cases and } \\
\text { controls? }\end{array}$} \\
\hline Were the statistical tests used to assess the main outcomes appropriate? & 1 & 1 & 1 & 1 \\
\hline Was compliance with the intervention/s reliable? & 1 & 1 & 1 & 1 \\
\hline Were the main outcome measures used accurate (valid and reliable)? & 1 & 1 & 1 & 1 \\
\hline TOTAL: & 4 & 4 & 4 & 4 \\
\hline \multicolumn{5}{|l|}{ Internal validity - confounding (selection bias) } \\
\hline $\begin{array}{l}\text { Were the patients in different intervention groups (trials and cohort studies) or were the cases and } \\
\text { controls (case-control studies) recruited from the same population? }\end{array}$ & 1 & 1 & 1 & 1 \\
\hline $\begin{array}{l}\text { Were study patients in different intervention groups (trials and cohort studies) or were the cases and } \\
\text { controls (case-control studies) recruited over the same period of time? }\end{array}$ & 0 & 1 & 1 & 1 \\
\hline Were study patients randomized to intervention groups? & 0 & 0 & 0 & 0 \\
\hline $\begin{array}{l}\text { Was the randomized intervention assignment concealed from both patients and health care staff until } \\
\text { recruitment was complete and irrevocable? }\end{array}$ & 0 & 0 & 0 & 0 \\
\hline Was there adequate adjustment for confounding in the analyses from which the main findings were drawn? & 1 & 1 & 1 & 1 \\
\hline Were losses of patients to follow-up taken into account? & 1 & 1 & 1 & 1 \\
\hline TOTAL: & 3 & 4 & 4 & 4 \\
\hline \multicolumn{5}{|l|}{ Power } \\
\hline $\begin{array}{l}\text { Did the study have sufficient power to detect a clinically important effect where the probability value for } \\
\text { a difference being due to chance is less than } 5 \% \text { ? }\end{array}$ & 1 & 1 & 1 & 1 \\
\hline TOTAL SCORE FOR GLOBAL QUALITY ASSESSMENT: & 19 & 21 & 21 & 20 \\
\hline
\end{tabular}




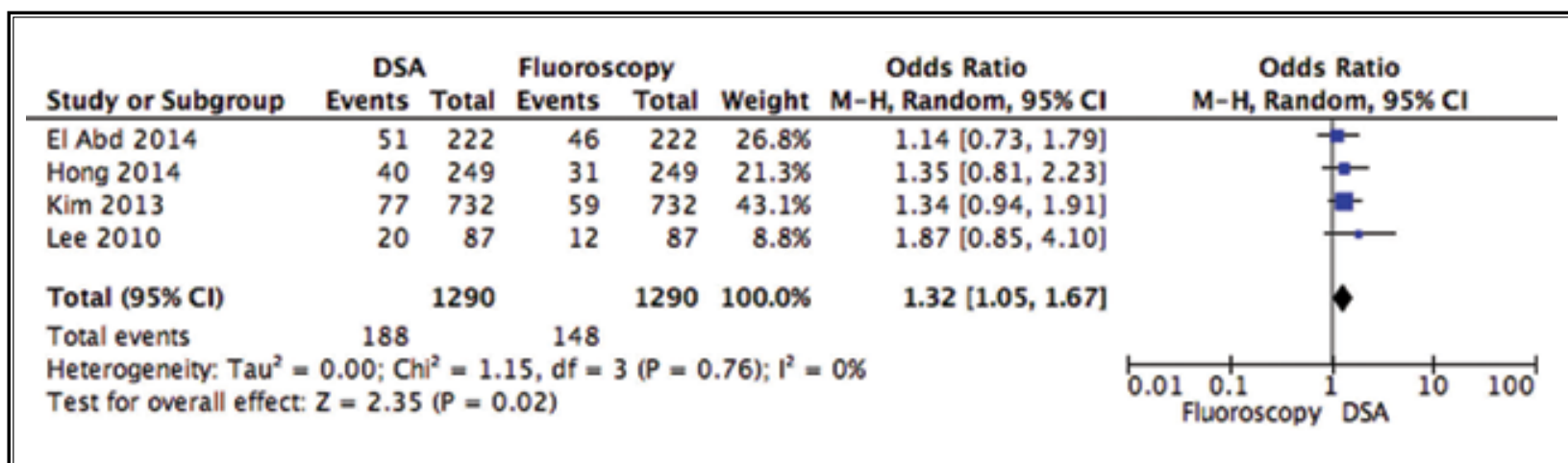

Fig. 2. Forest plot. Comparison of DSA versus RTF for detection of intravascular penetration during ESI.

with concurrent epidural spread, their detection may be more difficult with RTF than with DSA, which may explain why RTF appears to be a less sensitive technique $(3,4,6)$.

Although these findings support advocacy for the use of this technology, it also suggests that there is a greater than $30 \%$ "missed-events" rate for detecting vascular penetration when using RTF for ESI $(O R=1.32$, Fig. 2). This incidence of missed events is significantly greater than the generally reported cumulative rates of complications (approximately $1 \%$ ), which in and of themselves are generally minor complications with neurological injury comprising a small subset $(13,14)$.

As of yet, the determinants of this disparity between missed events and complication rates are unclear and likely multifactorial, but there are several theories and variables potentially contributing to complications of ESI. Direct needle trauma, vascular spasm, along with differences in sequelae from arterial versus venous events have been implicated to play roles in neurovascular injury following ESI, as has the particulate nature of various steroids and the use of blunt versus sharp needles $(1,2,15-17)$. Variations in neuraxial vascular anatomy may also play a significant role in predisposition to clinically significant vascular events $(18,19)$.

Notwithstanding the obvious improvement in detection rates of vascular events with the use of DSA, the disparity between this improvement and clinically significant patient complications suggests that vascular events are a single component in a multifactorial cascade that may be required for devastating complications to occur. Furthermore, DSA is not a perfect technique, as devastating injury following negative DSA imaging has been reported (20).

There were several limitations for this metaanalysis. First, the risk of bias during data collection and presentation cannot be eliminated. These studies were not blinded and although effort was made to limit bias within them, the interventionalist performing the procedure was not blinded to the outcomes being tested. One study excluded difficult procedures, which assists in providing a more uniform patient population for study, but also removes outliers that may benefit to a greater degree from the use of DSA. The anatomic location and the type of needle differed among the 4 analyzed reports as well. Three of 4 studies reported the use of Quincke needles, but varied in gauge (6-8). The fourth study reported gauge, but not type of needle (9). Two studies also noted difficulty discerning arterial versus venous contrast spread for vascular events, but the other 2 did not attempt to make this distinction. No significant neurological complications were reported for this study. The outcomes measured are limited to vascular events (Fig. 2) and patient complications (none reported), but did not include assessments of ESI efficacy, duration, or any other measurable outcomes. Furthermore, a sample of 1,290 ESI with 148 and 188 vascular events for RTF and DSA, respectively, although sizable and statistically significant, represents a small fraction of the ESI procedures performed globally, limiting generalizability of results and necessitating further study and larger sample sizes to substantiate these findings. Lastly, one study's methodology compromised the calculation of sensitivity and specificity within this meta-analysis because its positive outcomes were initially detected by RTF, but not confirmed by DSA (7). Rather, these positives were assumed to be positive for both RTF and DSA, compromising sensitivity and specificity assessments with RTF-positive data. RTF-detected negative outcomes were not affected, as they were followed by DSA imaging.

None of these studies reported the incremental in- 
crease in radiation exposure, which in itself may not be significant for each patient, but may become significant for the physicians and support staff choosing to employ DSA over RTF. DSA has been reported to increase the effective radiation dose incurred by $2.5-4.3$ fold for cervical transformational ESI and 2.3 - 4.2 fold for lumbar transformational ESI when compared to conventional fluoroscopy, where radiation doses ranged from 4.0 to $7.7 \mu \mathrm{Sv}$ in the cervical region and $22-38 \mu \mathrm{Sv}$ in the lumbar region (21).

The quality of the 4 studies included in this analysis was deemed to be moderate, but may be argued to be higher considering 2 points were lost because this study compared both DSA and RTF in the same patient, rather than randomizing patients to one technique or the other - a crossover design that limits variability between control and intervention assessments and is preferred in this scenario. Also, considering that experienced clinicians are required as observers to ensure the validity of recorded outcomes, it is impractical to assume that interventionalists or observers could be blinded to imaging technique as each of them could easily identify RTF versus DSA images. Nonetheless, this lack of practicality does not preclude the assessment of study quality, thereby classifying the quality of studies as moderate.

\section{Conclusions}

One of 2 conclusions may be drawn from these findings. On one hand, from the perspective of the health care resource utilization as a whole, with an additional consideration for a potentially dangerous increase in lifetime radiation exposure to clinicians, one might conclude that despite radiological sensitivity improvements, it may be unwarranted to label DSA as a standard-of-care for prevention of complications while performing ESI as such radiological improvements may not correlate with clinically significant patient outcomes given the multifactorial nature of devastating complications. On the other hand, for patients who suffer devastating complications resultant from vascular penetration, it is hard for physicians to subsequently justify their choice to forgo the use of DSA over RTF, especially when clear and significant evidence is available. Thus, we advocate for the increased use of DSA over RTF for transformational ESI.

\section{References}

1. Glaser SE, Shah RV. Root cause analysis of paraplegia following transforaminal epidural steroid injections: the 'unsafe' triangle. Pain Physician 2010; 13:237-244.

2. Rathmell JP, Michna E, Fitzgibbon DR, Stephens LS, Posner KL, Domino KB. Injury and liability associated with cervical procedures for chronic pain. Anesthesiology 2011; 114:918-926.

3. Hong JH, Kim SY, Huh B, Shin HH. Analysis of inadvertent intradiscal and intravascular injection during lumbar transforaminal epidural steroid injections: A prospective study. Reg Anesth Pain Med 2013; 38:520-525.

4. Smuck M, Fuller BJ, Yoder B, Huerta J. Incidence of simultaneous epidural and vascular injection during lumbosacral transforaminal epidural injections. Spine J 2007; 7:79-82.

5. Jasper JF. Is digital subtraction flouroscopy a useful tool for the interventional pain physician? Pain Physician 2002; 5:36-39.

6. Hong JH, Huh B, Shin HH. Comparison between digital subtraction angiography and real-time fluoroscopy to detect intravascular injection during lumbar transforaminal epidural injections. Reg Anesth Pain Med 2014; 39:329-332.

7. El Abd OH, Amadera JE, Pimentel DC Pimentel TS. Intravascular flow detection during transforaminal epidural injections: A prospective assessment. Pain Physician 2014; 17:21-27.

8. Kim YH, Park HJ, Moon DE. Rates of lumbosacral transforaminal injections interpreted as intravascular: Fluoroscopy alone or with digital subtraction. Anaesthesia 2013; 68:1120-1123.

9. Lee $M H$, Yang KS, Kim YH, Jung HD, Lim SJ, Moon DE. Accuracy of live fluoroscopy to detect intravascular injection during lumbar transforaminal epidural injections. Korean J Pain 2010; 23:18-23.

10. McLean JP, Sigler JD, Plastaras CT, Garvan CW, Rittenberg JD. The rate of detection of intravascular injection in cervical transforaminal epidural steroid injections with and without digital subtrac- tion angiography. PM R 2009; 1:636-642.

11. Downs SH, Black N. The feasibility of creating a checklist for the assessment of the methodological quality both of randomised and non-randomised studies of health care interventions. Journal of Epidemiology and Community Health 1998; 52:377-384.

12. DerSimonian R, Laird N. Meta-analysis in clinical trials. Control Clin Trials 1986; 7:177-188.

13. Malhotra G, Abbasi A, Rhee M. Complications of transforaminal cervical epidural steroid injections. Spine (Phila Pa 1976) 2009; 34:731-739.

14. McGrath JM, Schaefer MP, Malkamaki DM. Incidence and characteristics of complications from epidural steroid injections. Pain Med 2011; 12:726-731.

15. Kennedy DJ, Dreyfuss P, Aprill CN, Bogduk N. Paraplegia following imageguided transforaminal lumbar spine epidural steroid injection: Two case reports. Pain Med 2009; 10:1389-1394.

16. Smuck M, Leung D. Inadvertent injec- 
tion of a cervical radicular artery using an atraumatic pencil-point needle. Spine (Phila Pa 1976) 2011; 36:E220-E223.

17. Tiso RL, Cutler T, Catania JA, Whalen K. Adverse central nervous system sequelae after selective transforaminal block: The role of corticosteroids. Spine J 2004; 4:468-474.

18. Huntoon MA. Anatomy of the cervical intervertebral foramina: vulnerable arteries and ischemic neurologic injuries after transforaminal epidural injections.
Pain 2005; 117:104-111.

19. Okubadejo GO, Talcott MR, Schmidt RE, Sharma A, Patel AA, Mackey RB, Guarino AH, Moran CJ, Riew KD. Perils of intravascular methylprednisolone injection into the vertebral artery. An animal study. J Bone Joint Surg Am 2008; 90:1932-1938.

20. Chang Chien GC, Candido KD, Knezevic NN. Digital subtraction angiography does not reliably prevent paraplegia associated with lumbar transforaminal epidural steroid injection. Pain Physician 2012; 15:515-523.

21. Maus T, Schueler BA, Leng S, Magnuson D, Magnuson DJ, Diehn FE. Radiation dose incurred in the exclusion of vascular filling in transforaminal epidural steroid injections: Fluoroscopy, digital subtraction angiography, and CT/fluoroscopy. Pain Med 2014; 15:1328-1333. 